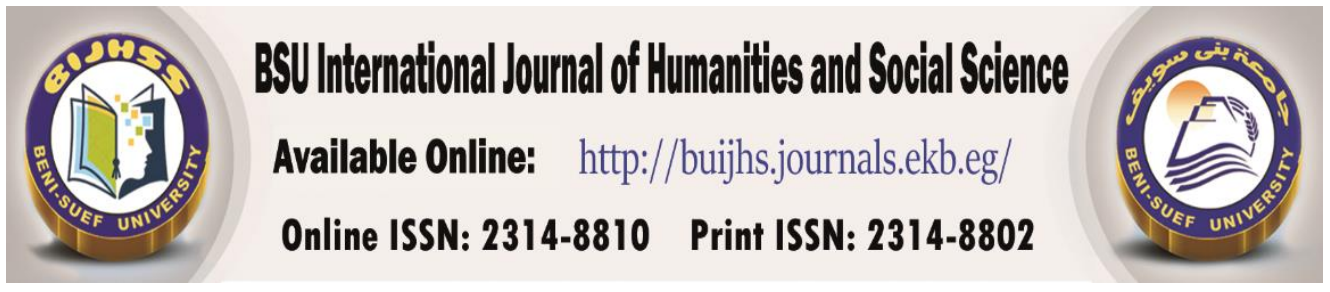

\title{
Las formas apocopadas y sincopadas en Jarrapellejos de Felipe Trigo
}

\author{
Dr_Abdel Aziz Hassan Fahd \\ Assistant Professor Spanish Depatament, Faculty of Arts,Zagazig University, Zagazig, Egypt
}

\begin{tabular}{l|l} 
ABSTRACT & $\begin{array}{l}\text { This study deals in its first part with presenting } \\
\text { a brief overview of the most important characteristics } \\
\text { of the colloquial/vulgar language. The second part is } \\
\text { concerned with analyzing the phenomenon of } \\
\text { omission and words that have been affected by the } \\
\text { mechanics of omitting such as syncopation, } \\
\text { Received } \\
\text { accepted }\end{array}$ \\
\hline & $\begin{array}{l}\text { agglutination and apocope. The study also shows the } \\
\text { omission mechanisms that the writer uses in his novel } \\
\text { uarrapellejos de Felipe Trigo and that the aim of } \\
\text { nature of the dialogues between the protagonists. } \\
\text { Moreover, the linguistic forms mostly affected by } \\
\text { omission in the novel are highlighted. } \\
\text { colloquial language, vulgar language, apocope, } \\
\text { syncopation }\end{array}$
\end{tabular}




\section{Introducción}

En el presente trabajo no se va a tratar el lenguaje coloquialvulgar, ni a revisar el desarrollo cronológico de las formas apocopadas y sincopadas en la lengua española a lo largo de este espacio. Mi objetivo fundamental es descubrir los aspectos de dichas formas como recursos lingüísticos, desde el nivel fonético, que están adaptadas al lenguaje coloquial-vulgar, que tienen gran representación en la novela Jarrapellejos de Felipe Trigo y que constituye nuestro corpus de referencia. Cabe destacar que el presente estudio solo se limita a precisar la alternancia entre los dos fenómenos más utilizados: la apócope y la síncopa en cuanto a los sistemas gráficos y su pronunciación.

En función de ello, hemos dividido el estudio en dos partes: en la primera se perfila un escueto panorama sobre las características generales (lenguaje coloquial-vulgar) $\mathrm{y}$, asimismo, de lo que se entiende por palabras apocopadas y sincopadas. En la segunda, se analizan en detalle los textos extraídos de la obra citada, elegida como base de este trabajo por muchas razones, entre ellas, la abundancia de ejemplos que representan las dos formas reducidas.

Es de todos sabido que la apócope y la síncopa son procesos fonológicos que se basan en la desaparición de uno o varios sonidos. En el primero, la omisión tiene lugar en posición final de palabra, mientras que el segundo consiste en perder la vocal o sílaba en el medio de la palabra.

\section{Características del lenguaje coloquial-vulgar}

La lengua española, como todos los idiomas, posee una gran riqueza de variedades: dialectales, jergales, populares, coloquiales y vulgares, que influyen en los hablantes del lenguaje tanto escrito como oral. A este respecto, Moreno Bernal (2004: 195) indica que el castellano se caracteriza «por una pluralidad de formas en el plano fonético [...] y disponía por lo mismo de una gran riqueza de medios 
para hacer variado el discurso». El punto de partida de nuestra atención es el lenguaje coloquial-vulgar, que representa un variante léxica más adaptada a la conversación diaria, a situaciones de informalidad, y se acerca más a la lengua oral. Por otro lado, se caracteriza por muchos vocablos de matices de germanía o voces dialectales. Por tanto, se han registrado algunos vulgarismos en el habla coloquial.

El lenguaje coloquial-vulgar se puede insertar en cualquier texto transmitido entre los interlocutores y mezcla rasgos vulgares y marginales. En opinión de Rebollo Torío (1998: 322) «se puede intercalar con vulgarismos una conversación coloquial, pero no necesariamente un lenguaje coloquial ha de recurrir por fuerza a lo vulgar» Y continúa diciendo: «el lenguaje está salpicado de vulgarismos y formas del marginalismos». En este sentido, cabe añadir las palabras de Garriga (1994: 10), quien, explica que las palabras que agrupamos bajo la marca vulgar se clasifican en tres grupos: el primero, las palabras que denotan conceptos tabú; el segundo se refiere a los vocablos que pertenecen al lenguaje de los marginales; mientras el tercer grupo lo constituyen las expresiones arcaicas «que se mantienen en las zonas rurales, consideradas poco cultas».

Antonio Briz (1996: 3-29) hace una referencia a los rasgos principales del lenguaje coloquial y señala que este no es propio de una clase, sino de todos los hablantes de una lengua. Y se caracteriza por incorporar dialectos y sociolectos de los usuarios del lenguaje. Se manifiesta tanto en el oral como en el texto escrito y aparece en varios tipos del discurso. El citado autor sigue explicando el tipo de diferencia entre el lenguaje coloquial y lenguaje vulgar. Este aparece cuando se da un uso incorrecto, es decir, al salirse de la norma estándar, generalmente por razones como la ignorancia del usuario, mientras que el lenguaje coloquial el autor lo considera como un tipo de habla socialmente aceptado, dentro del cual se hallan vocablos vulgares y dialectales, y depende del usuario. Para Manuel Seco (1985: 368) el coloquial «es un registro elegido por el usuario en función de la situación en que se produce el acto de comunicación». 
A. Briz explica en otra publicación (2001: 40) que el lenguaje coloquial «es un registro empleado dependiendo de la situación comunicativa sin ser exclusivo de una clase social». Se entiende por las palabras de este autor que el lenguaje coloquial no es uniforme para todos los hablantes; tampoco se relaciona con ninguna clase y puede aparecer tanto en el lenguaje oral como en el escrito. Para Cascón Martín (1996: 13) el lenguaje coloquial se basa en el diálogo, la espontaneidad y el uso, con mucha frecuencia, de la elipsis, a fin de economizar el habla, incluye un conjunto de expresiones lexicográficas jergales, vulgares y de argot. Tales expresiones, a veces, funcionan como formas metafóricas.

Según lo expuesto arriba, aquí pueden sintetizarse algunas características del lenguaje coloquial:

a) El lenguaje coloquial se basa en el intercambio entre los interlocutores, de modo que incluye todas las actividades del habla humana (mensajes, cualquier tipo de acción consistente en dar y recibir información).

b) Es un lenguaje oral y, al mismo tiempo, es empleado por los dramaturgos y novelistas para conseguir rasgos propios, relacionados con el carácter de sus personajes en el acto de comunicación.

c) Por otro lado, se caracteriza por la naturalidad y la espontaneidad en el habla, es decir se aleja un poco de las reglas gramaticales.

d) La abundancia de la elipsis, por razones de economía lingüística.

e) Se caracteriza por las diferentes variedades dialectales, populares y sociales.

f) Se manifiestan en el lenguaje coloquial algunas peculiaridades relacionadas con otros elementos, como el lugar de residencia, la clase y el dialecto. 
R. Lapesa (1981: 466-475) considera el vulgarismo «como variedad social de gran interés [...] existen usos cuyo radio de acción está hoy limitado a gentes iletradas de las aldeas y a las capas populares de la ciudad». Sigue explicando que se encuentran muchos vocablos vulgares con gran aprobación en las obras literarias. Aunque el citado autor señala muchos rasgos del vulgarismo, destacamos aquí únicamente aquellos que aparecen registrados en la obra tratada:

a) La relajación de las consonantes /d/, /g/, y /r/, las más afectadas en lenguaje corriente, especialmente, en el vulgar.

b) En la pronunciación vulgar se elimina la /d/, la pérdida da lugar a la fusión de vocales.

c) La abundancia de suprimir la /d/ al final de la palabra. Este fenómeno se utiliza con mucha frecuencia en todas las regiones de España.

d) La desaparición de la /r/ en las palabras de fácil uso, como el tratamiento.

e) A veces la supresión afecta a las formas verbales; tal proceso radica en la reducción de dichas formas.

f) La separación limitada de palabras permite el desarrollo del proceso de aglutinación entre vocales, especialmente la desaparición la /d/ de la preposición /de/.

g) Se agrupan preposiciones y artículos ante la vocal /-e/ de los pronombres personales, de /me/, /te/, /se/. Tal eliminación se remonta al habla culta del siglo XVII.

h) En cuanto a la morfología vulgar, se ha registrado una abundancia de formaciones muy desusadas semejantes a las de subjuntivo.

\section{Las formas apocopadas y sincopadas}

Dentro de las formas reducidas, cabe destacar dos fenómenos de gran relevancia: la apócope y la síncopa, las cuales son propias de la 
lengua oral y se basan en omitir letras, es decir, eliminar o hacer desaparecer una o varias sílabas. La apócope consiste en eliminar uno o varios sonidos en la posición final de algunas palabras. Mientras que la forma sincopada será aquella en la que han sido suprimidos uno o más sonidos del interior de un vocablo. Es decir, se trata de comerse algunas letras o sílabas completas, o solamente una letra, en la pronunciación, tanto al final como en el medio de la palabra, de manera que, el nuevo vocablo sigue manteniendo el mismo significado, sin sufrir ningún cambio en su categoría gramatical. Tales fenómenos se acercan más a la lengua oral que a la escrita, puesto que en la primera los interlocutores no se preocupan mucho por las normas gramaticales.

Dicho fenómeno se utiliza, con mucha frecuencia, tanto en el lenguaje oral como en el texto escrito y afecta a todas las categorías gramaticales, con el fin de facilitar y contribuir a la rapidez en la pronunciación de los hablantes. Cabe destacar además que las citadas formas no se limitan a una determinada clase, sino que están extendidas y son empleadas en cualquier clase de la sociedad.

Los diccionarios de la lengua española han dado definiciones muy parecidas de los dos términos tratados: la apócope y la síncopa, las cuales se remontan a raíces más lejanas de la lengua griega y pasaron del latín al español. Conviene recordar aquí la definición dada por el DRAE (2019), que dice que la apócope es la «supresión de algún sonido al final de un vocablo, como en primer por primero», mientras que la síncopa consiste en la «supresión de algún sonido dentro de un vocablo, como en debrías por deberías». Generalmente, son conceptos que se usan para denotar la omisión de una letra o de una sílaba tanto en el medio como al final de algunas palabras.

Respecto a este fenómeno, Narbona Jiménez (1988: 247) dice que la «abundancia de las construcciones supuestamente suspendidas, sincopadas o incompletas que ofrece la lengua coloquial no debe verse como simples acortamientos provocados por una voluntad». Por tanto, 
se puede decir que esta reducción se debe a la falta una de las destrezas idiomáticas.

Carlos Folgar (2012:331) señala que hay que subrayar una peculiaridad muy llamativa del fenómeno en cuestión: una «variante apocopada implica una reducción en el cómputo silábico: la forma plena presenta un número de sílabas $n$, mientras la forma con apócope tiene un número $n-1 \gg$. El citado autor indica a las formas apocopadas relacionadas con los pronombres átonos, particularmente los personales $m e$, te, le y el reflejo $s e,\left(m e>m^{\prime}, t e>t^{\prime}, l e>l\right.$,' lo $>l$, se $>s^{\prime}$ ) y considera que la apócope aquí «genera alguna modificación adicional, de cierta relevancia». Y añade que tales apócopes "se encuentran condicionadas por la fonética sintáctica, y son de carácter opcional cuando la forma personal va enclítica a otra palabra».

Antes de pasar a la parte práctica del presente trabajo, planteamos algunas preguntas: ¿por qué el escritor mezcla en su obra estos fenómenos?, ¿por qué el escritor recurre a emplear este recurso en el texto escrito? ¿Le sirve para adaptar palabras orales a la escritura? En realidad, al usar este estilo, el autor quiere indicar muchas cosas, entre ellas, destacar las caracterizaciones de sus personajes, así como transmitir el color local. Por otro lado, el escritor intenta reproducir la forma de hablar de sus personajes en el transcurso de la obra.

Observamos que Felipe Trigo pretende caracterizar sus figuras en la novela con el habla coloquial-vulgar, que se manifiesta en sus diálogos, particularmente, cuando sus personajes hablan de manera informal. Como se ha dicho antes, el autor pretende emular este tipo de recurso fonético para añadir el color local de la región extremeña a sus personajes. Cabe decir también, que Jarrapellejos contiene muchos tipos de metaplasmos, de adición, de supresión y transposición. Como ya hemos indicado, nuestro estudio se centra solo en las formas apocopadas y sincopadas. A continuación se estudia el empleo de las formas reducidas, apócope y síncopa, más frecuente en la obra tratada: 
(1) "Qué alcalde, don Pedro Luis, vaigan con Dios y con salú; qué alcalde de mi arma! ¡Bien sabemos que sin la voluntá de usté no se menea por toa esta tierra ni un mosquito". (p. 47)

(2) " [...] y a pesá del dineral que las ofrece..., y vea óste aquí que como esto del necesitá....por el fuego de anoche se pué metel al padre en chirona, y quear a dambas en el brete de que no tengan más remedio que ablandase". (p.54)

(3) "Qué ha de sucedé, sino que nos quean sin pan los bicho, que to le han repelao!" (p 74)

(4) - "A la pá e Dio". (p. 95)"

(5) - " Vaya un diíta, ¿eh? Pa los que no tenemos más remedio que chincharnos. ni las cigarra ni las jormiga han salío de sus bujero. ¡Tra cá un cigarro, Melchó!" (p. 95)

(6) "Qué tierra nuestra tierra, Dios! ¡Maldita sea! Salí de aquí a la siega me paece una tontuna". (p. 98)

En los ejemplos que acaban de mencionarse se nota que el escritor utiliza las dos formas, tanto las apocopadas como las sincopadas. En primer lugar, se observa el uso de la apócope en los ejemplos (1-6): la pérdida de la consonante final de algunas palabras como /salud $>$ salú/, /voluntad $>$ voluntá/, /usted $>$ usté/, /usted > osté/, /necesitad > necesitá/, /pesar $>$ pesá/, sucedé $>$ suceder/, /paz $>$ pá/. /Dios $>$ Dio/, /tras $>$ tra/, /salir, salí/, /Melchor $>$ Melchó/, nombre propio. También hay supresión de la sílaba final en las siguientes formas: /puede $>$ pué/, /pa $>$ para/, /to $>$ todo/, cada $>$ cá/.

En segundo lugar, se registra el empleo de palabras sincopadas en (1-6): la omisión de la consonante /-d/ en /toda > toa/, quedar, quear/, /quedan $>$ quean/, /repelado $>$ repelao/, salido $>$ salío/, y la /-r/ en $/$ parece $>$ paece/.

Cabe señalar también otro fenómeno que, aunque muy escaso, se basa en eliminar la /-d/ de la preposición /de/, como se ve en la siguiente frase /a la paz de Dios > a la pá e Dios/. 
Según lo expuesto, se puede decir que la apócope y la síncopa como recurso lingüístico afectan a todas las categorías gramaticales: sustantivo, verbo, adjetivo, preposición, aunque se nota el predominio de los sustantivos, incluso el nombre propio, sobre las demás categorías.

(7) " Pues sabrás, padre, que debo decirte también que aquí no hay pobres, porque tos tienen pa comé na ajorrá con su trabajo, y no permitirían tampoco echase a las calles a pedí; pero sabrás, padre que el otro día estaba yo a comprá una purga en la botica, y entró un ciego y sin decil na comenzó a sacarse del bolsillo puñaito, y otro de moneas de a dos reales". (p. 99)

(8) " [...] que me dijo que era lo que venía a cambiale toas las noches de lo que sacaba de dejale pedí en la avenía de Mayo por sel ciego". (p..99)

(9) - " Pa gorvel? -desconfió uno".

- Hombre, Moro, pa gorvel ca cual cuando quía y que la paezca". (p.100)

(10) - "Bah, hombre, que limpie el señó arzobispo ...tra cá cigarro". (p.100)

(11) "Despué de to, lo que se deja de hacé es lo que se saca de la vida, " (p.101)

(12) " Y no es que yo me puá quejá, que bien ves tú si me quieren o no y si me meman los señore..., pero, ¡vamo!, A que no tengamos na pa que ellos tengan to, es $\boldsymbol{m} \boldsymbol{u}$ duro resinase". (p. 101)

(13) - " ¿Por qué fue, tío Ramas, por lo que estuvo usté en persillo?" (p.101)

- "Por na; por dale unos trompis al aperaó de don Andrés Rivas, hasta queale sin sintío". (p.101)

(14) "Don Fulano, si usté quisiá haceme el favó de argo, porque anda uno tan mal con su sueldo tan chico y tantas bocas en la casa..." (p. 102) 
(15) - " ¡Mira, mira, qué de golosos, la Isabel!..., ¡na má de asuponerse que vendría donde esta tarde! ¿Qué suerte la de argunas!" (p.103)

En estos textos el escritor utiliza la forma apocopada con mucha frecuencia, que se funda, pues, en suprimir la consonante final de la palabra en verbos: /comer > comé/, /pedir > pedí/, /comprá > comprar/, /hacer > hacé/, /quejar > quejá/, /vamos > vamo/; y sustantivos: /señor $>$ señó/, /usted > usté/, /favor, favó/, /señores > señore/. También en adverbios: /más $>$ ma/, muy $>$ mu/, /después $>$ despué/. Además, la apócope se basa en eliminar la sílaba final de una palabra: /todo $>/$ to/, /cada > /cá/; el pronombre indefinido /nada $>$ na/; la preposición /para $>$ pa/. E influye así en las formas verbales /pueda $>$ pué/. Podemos añadir además que la omisión de una consonante intervocálica provoca la fusión de vocales iguales.

En cambio, la forma sincopada se basa en suprimir una o más consonantes del interior de la palabra. El escritor emplea este recurso fonético con poca frecuencia: /quería $>$ quiá/, / parezca $>$ paezca/, / quisiera $>$ quisiá//avenida $>$ avenía/, /todos $>$ tos $/{ }^{1}$.

(16) " [...] ¡Mira quienes más vien’ a caballo p’allí!"(p. 204)

(17) " [...] “iQuién es? - la señá Cruz la del tío Roque Salzar. Mu apurá la pobretica". (p.120)

(18) "[...] y a pesá del dineral que las ofrece..., y vea óste aquí que como esto del necesitá....por el fuego de anoche se pué metel al padre en chirona, y quear a dambas en el brete de que no tengan más remedio que ablandase".

\footnotetext{
1 En los ejemplos (7-15) se pueden apreciar otros fenómenos como la asimilación. Lingüísticamente, se trata de una alteración en la articulación de un sonido para asemejarse a otro inmediato o próximo /decir-decil/, /ser-sel/. También se produce una neutralización entre /1/ y /r/ al final de sílabas o palabras, como /algo, argo/, /algunas, argunas/ y una aspiración, es pronunciar la letra /h/ con un sonido más débil que el de la /j//como /ahorrar-ajorrá/.
} 
(19) " ¡Hombre, tú! -intervino Octavio-, ¡Haz el favor! ¡Hala ahí denro!" (p.191)

(20) " ¡Al pelo! ¡Al pelo! ¡Vaya un mozo que está usté, don Mariano!" (p.227)

(21) - "Pues tenga la llave, y abra cuando vea sola la calle, y no haigan de golverlo ni las moscas". (p.227)

(22) "Saturnino había hecho un ademán de lanzarse, buscándose el puñal en el bolsillo; Gregorio le hbía dado una bofetada de revés..." (p.308)

(23) - "Hasta allí. Una, mecachis, gitanota, con un rejo...pintá toa por toas partes de lunare". (p.309)

(24) - "Pa luego es tarde, salvo que lo que aquí don Mariano le paezca. Melchor está en su cuarto durmiendo pué dir por los caballos; ya tengo mi mula". (p.309)

(25) - "Quiten p'alla, hombre, ahora molestarse en andal diendo y gorviendo. ¿Cualiscual quieren ostés?" (p. 310)

(26) - " ¡Como si quié osté disponé de toa mi casa y mi persona!" (p. 311)

(27) - " ¡Melchor! ¡Me caso en diez, ni que s'habiá (hubiera) topao los jacos en la esquina!" (p.311)

(28) - "Hola, tío Ramas - prosiguió, dominando sus recuerdos-, ¡Perdón, si es qu’importuno! Venía, había salío de casa olvidándome los chisques de encender, y por no golver p'atrás..." (p. 311)

En los ejemplos mencionados anteriormente (16-28) notamos que el autor utiliza otro mecanismo fonético: la contracción, la cual se emplea con gran abundancia en la obra en cuestión. Este fenómeno responde en la novela a dos estructuras: la que se forma con verbo + preposición — viene a caballo > vien' a caballo/_ y la formada por preposición + adverbio —/ p'allá, $>$ para allá/,/para atrás $>$ p'atrás/- 
Además encontramos ejemplos que reflejan la pérdida de una letra o sílaba al final de la palabra, como / señora > señá/, /pesar > pesá/, / necesitad $>$ necesitá/, /muy $>$ mu/, /pintá $>$ pintar/; /lunares $>$ lunare/, $/$ para $>$ pa/,/puede $>$ pué/. Merece especial atención, la apócope de /-e/ ante vocal /me, te, le, que y se/, /se hubiera $>$ s'habiá/, /que importuno $>$ qu'importuno/.

Se ven también en los citados textos, distintas formas sincopadas como, /dentro $>$ denro/, /quiere $>$ quié/, quedar $>$ quear/, hubiera $>$ habiá/, cuando la consonante es difícil de pronunciar. Además, se constata el empleo de una morfología vulgar en el uso de arcaísmos cuya formación es semejante a las conjugaciones del modo subjuntivo como /haigan, vaiga/, equivalentes a hayan y vaya, respectivamente

(29) - " ¡"Quién, quién! -repetía más próxima la voz.

- Gente de paz, señá Cruz. Soy un sereno. Haga osté el favó de abrí, que venimos a un encargo de tío Roque.

¿De quién?

- de su marío

- ¿Pues qué le pasa a mi marido?

- Na, no le pasa na; no s'alarme, señá Cruz, que no es na. Es que se iba pa la feria y se encontró a Pablillo el herraor, que viene aquí conmigo, y que también $\boldsymbol{p a}$ dirse a la feria estaba preparando la burra a la puerta de su casa; entonces s'acordó qu'habia orvidao los chisques y unas sogas de maneo, y afué y le encargó tuviá l'amabeliá de venir a recogerlas y llevalas y pa tenelas en Trujillo". (p. 318)

(30) - " ¿No m'a oído usté, señá Cruz?

- Sí, sí que le he oído. Pero... ¿Quién dice usted que viene con

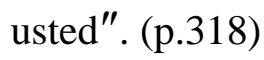

(31) - "Estaba abierta, seña Cruz, se comprende que ostedes o tío Roque la quearon cerrá en farso". (p. 319)

(32) - "Las sogas pa maneos..., por si tié que quear a parao las mulas". (p. 320) 
(33) " [...] d'aquí a menos de dos horas, en la cárcel. Lo siento por ostés..., y también, vaya, sus miajas, porque los hombres, metios en un negocio, han de sel hombres hasta el fin. De $\boldsymbol{m o}$ y manera que... ¿qu'hacemos, don Mariano, y osté tamién, don Saturnino?... ¿Ar pueblo..., o ar presillo y ar mataero ahora pa nosotros...como chivos atontaos?" (p. 329)

(34) " [... ¿Le conoció usted? No, señó. Últimamente me paeció qu'era un señorito". (p. 349)

(35) - "Debo confesal que aquella noche, señó jué (y a mi hombre selo dije) me paeció mesamamente el que corría el señorito Saturnino, el sobrino del señol conde, poco majo meno del cuerpo y naturá d'este señol; no salío de dambos de nosotros, por sel tan grave, al sabel meyodia que habían matao a las de Larmita, [...] “¡Fue el d'anoche!” Y ahora, señol jué, al vel a este señol y sabel que este señol mató a las probes de mi arma, que clavás las teno aquí. ¡Dios premita castigalme si m'engaño!, pero tengo que decirlo: fue el qu'aquella noche pasó juyendo por mi puerta". (P.350)

(36) - " ¿De quién? ¿D'este señó?...No lo puó explicá de mó ninguno". (p. 365)

(37) " [... ¿Es que así, sin más ni más, pa matá un cristiano, por cien cochinas pesetas cré osté que se pué comprá un hombre como yo, que gana er triple en una hora que quía en su oficio regolverse?... ¿Es, además, que cré osté que en toa su via ha podío tenel este señó pa mandal rezal a un ciego?". (p. 366)

(38) - "Pero, don Juan... ¡d'aquí a unos días!

- Pero, don Juan... ¡ icuando descanse!

¡Claro está! ¡Siquiá mañana! ¡Paicería, si no, que l'echamos de la casa, que no l'hamos querío ni recogé!". (p. 387)

(38) " ¡Qué? -le interrumpieron-, ¡Por Sios, don Juan, por Dios!---i Si $\boldsymbol{n}$ 'ha dejao de girarnos su familia, que n'habia pa qué pa na!" (p. 388) 
Resulta muy interesante destacar aquí qué se entiende por el término de «aglutinación» o «contracción» en el contexto de la forma apocopada, la cual consiste en combinar verbos y palabras con categorías gramaticales como preposiciones, pronombres, artículos. Fundamentalmente, pues, se trata de agrupar dos unidades en una sola forma compuesta. Fraile Vicente (2003: 18) explica que, con esta adaptación se pretende «reflejar el mimetismo entre la escritura y su manifestación oral». En esta línea, la citada autora afirma que la aglutinación o contracción no son más que «fenómenos de naturaleza mixta que pueden dar como resultado palabras ilógicas y de difícil pronunciación».

Para el DRAE (2019) la aglutinación consiste en «unir o pegar una cosa con otra de modo que resulte un cuerpo compuesto». Se entiende de esta definición que en este fenómeno se trata de unir dos palabras con diferentes significados en una sola palabra o una unidad sintagmática.

Hemos constatado la abundante utilización por parte del escrito de la apócope de /-e/ ante la vocal en /me, te, se, le, que, de/. Veamos ahora como se unen dos unidades de distintas categorías gramaticales y diferente significado formando una sola palabra compuesta: pronombre + verbo, que + verbo, preposición + adverbio, preposición + sustantivo, o incluso partícula negativa + verbo. Recogemos aquí algunas de las muestras más representativas del fenómeno de la aglutinación: /m'engaño - me engaño/, /qu'era - que era/, /no s'alarme -no se alarme/, /l'echamos - le echamos/, /s'acordó qu'habia orvidao - se acordó que había olvidado/, /l'amabeliá - le amabilidad/, /d'aquí-de aquí/, /d'anoche - de anoche/, /qu'aquella - que aquella/, /¿qu'hacemos - que hacemos/, /d'este señol - de este señor/, /n'ha dejao - no ha dejado/.

Merece igualmente la pena destacar otros ejemplos de palabras apocopadas: /señora $>$ seña/, /señor $>$ señó/, /usted $>$ usté/, /juez $>$ jué/, así como otras formas verbales: /cerrar $>$ cerrá/, /matá $>$ matá/, /recoger 
$>$ recogé/, /explicar $>$ explicá; preposición /para $>$ pa/ y pronombre indefinido $/$ nada $>$ na/, /modo $>$ modo/. Estos ejemplos ponen de manifiesto como la apocope afecta a distintas clases gramaticales (sustantivos, verbos, preposiciones, pronombres indefinidos, etc.). Cabe añadir, por último, otras formas sincopadas como /toda $>$ toa/, /también $>$ tamién/, señora $>$ seña/, /puede $>$ pué/, /pudo $>$ puó/, /tiene $>$ tié /, quería $>$ quía/, /quearon $>$ quedaron/, /quedar $>$ quear/, /querido $>$ querío/, /herrador, $>$ herraor/, /matadero $>$ mataero/, /parecería $>$ paicería/, /podido $>$ podío/, /olvidao $>$ olvidado/.

\section{Conclusiones}

En resumen, nos encontramos ante una serie de textos, recogidos en nuestro corpus, de los que se han elegido algunas muestras representativas para su análisis, en entre las muchas que hemos encontrado en la obra tratada. Hemos observado que el escritor intenta transcribir la conversación y las peculiaridades características del lenguaje de sus personajes con el fin de añadir un color dialectal.

Apreciamos también que el autor utiliza las formas reducidas, apocopadas y sincopadas como un recurso fonético para manipular las palabras, mediante la eliminación de una letra o silaba (sonido) tanto al final como en el medio de la palabra, con el objeto de imitar los diálogos de carácter coloquial-vulgar de los interlocutores.

Después de analizar el corpus, hemos podido identificar algunos rasgos relevantes en la novela tratada: a) la eliminación de la /d/ intervocálica, en particular, en las terminaciones de las palabras; b) la desaparición de la consonante final, tanto en la sílaba como en las palabras; c) las letras /r/ y /s/ son las que sufren en mayor medida la omisión.

En definitiva, hemos comprobado también el uso la técnica de la aglutinación o la contracción: agrupar dos unidades en una sola palabra, a través de la inclusión de un apóstrofo entre los dos lexemas, 
que ocupa el lugar del elemento suprimido. Tal fenómeno afecta, en menor o mayor medida, a todas las clases gramaticales, especialmente al verbo, al adjetivo, al adverbio y a la preposición. 


\section{Referencias bibliográficas}

\section{Libros}

- Trigo, Felipe (1988): Jarrapellejos, Madrid, Espasa Calpe.

\section{Estudios}

- BRIZ GÓMEZ, Antonio (1996): El español coloquial: situación y uso, Madrid, Arco/Libros.

“ “ (2001): El español coloquial en la conversación: esbozo de pragmagramática, Barcelona, Ariel.

- CASCÓN MARTÍN, Eugenio (1996): Español coloquial. Rasgos, formas y fraseología de la lengua diaria, Madrid, Edinumen.

- GARRIGA, Cecilio (1994): “ la marca de 'vulgar' en el DRAE: De Autoridades a 1992.Sintagma, 6, pp. 5-13. Disponible en https://www.academia.edu/22609488/La_marca_de_vulgar_en_el_DR AE_de_Autoridades_a_1992. (Fecha de consulta: 11/5/2019)

- FOLGAR, Carlos: "Restitución, estructura vocálica de sílaba. Observaciones sobre los pronombres clíticos apocopados". https://core.ac.uk/reader/75992832. (Fecha de consulta: 1/4/2019)

FRAILE VICENTE, E. (2003): "La traducción de los rasgos morfosintácticos del inglés coloquial", en Revista de Traducción e Interpretación, núm.5, pp. 1-23.

- LAPESA R. (1981): Historia de la lengua española, Madrid, Gredos.

- MORENO BERNAL (2004): "Los condicionamientos de la apócope en los textos castellanos antiguos", en Revista de Filología Románica núm. 21, pp. 181-199.

- NARBUNA JIMÉNEZ A. (1988): "Problemas de sintaxis coloquial andaluza" en revista española de lingüística, núm.12. fasc.2, pp-229267. (Fecha de consulta 24/7/ 2019)

- REBOLLO TORÍO, Miguel Á. (1998): "El jueves y el lenguaje hablado" en Anuario de Estudios Filológicos, núm. XX1, pp. 319-328. 
- SECO, M. (1985): "La lengua coloquial": 'entre visillos', de Carmen Martín Gaite", en El comentario de textos, I, Madrid, Castalia.

- REAL ACADEMIA ESPAÑOLA (2019): Diccionario de la Lengua Española, ed. tricentenario, actualización 2010, disponible en https://dle.rae.es/ap\%C3\%B3cope https://dle.rae.es/s\%C3\%ADncopa. (Fecha de consulta: 30/4/2019) 